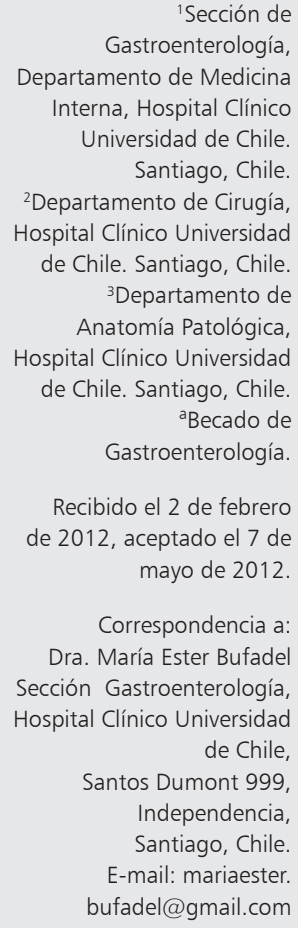

'Sección de

Gastroenterología,

Departamento de Medicina Interna, Hospital Clínico Universidad de Chile. Santiago, Chile.

${ }^{2}$ Departamento de Cirugía,

Hospital Clínico Universidad de Chile. Santiago, Chile.

${ }^{3}$ Departamento de

Anatomía Patológica,

Hospital Clínico Universidad de Chile. Santiago, Chile. aBecado de

Gastroenterología.

Recibido el 2 de febrero de 2012, aceptado el 7 de mayo de 2012

Correspondencia a: Dra. María Ester Bufadel Sección Gastroenterología, Hospital Clínico Universidad de Chile,

Santos Dumont 999, Independencia, Santiago, Chile.

E-mail: mariaester. bufadel@gmail.com

\section{Enfermedad de Ménétrier con compromiso gástrico difuso y duodenal. Caso clínico}

\author{
MACARENA GOMPERTZ ${ }^{\text {la }}$, CRISTIÁN MONTENEGRO ${ }^{1, \mathrm{a}}$, \\ MARÍA ESTER BUFADEL ${ }^{1}$, CARLOS DEFILIPPI ${ }^{1}$, \\ JAIME CASTILLO ${ }^{2}$, CLAUDIA MORALES ${ }^{3}$
}

\section{Ménétrier disease. Report of one case}

Ménétrier disease is a rare disorder of the stomach, characterized by giant hypertrophic folds that usually involve the gastric body and fundus, associated to hypoalbuminemia due to serum protein loss across the gastric mucosa. We report a 55-years-old male presenting with abdominal pain, vomiting, weight loss and hypoalbuminemia. Diffuse hypertrophic gastric folds, elevated ulcerated sessile lesions and focal duodenal involvement were seen at endoscopy. Biopsies showed foveolar hyperplasia and glandular atrophy with cystic dilatation. A total gastrectomy was performed with a good outcome.

(Rev Med Chile 2012; 140: 1174-1178).

Key words: Gastritis, hypertrophic; Hypoalbuminemia; Ménétrier disease.
L

a enfermedad de Ménétrier es una entidad poco frecuente caracterizada por la presencia de pliegues gástricos engrosados. La mucosa gástrica afectada secreta cantidades masivas de mucina lo que conlleva a pérdida de proteínas acompañada de hipoalbuminemia y edema. Histológicamente se observa hiperplasia foveolar masiva asociada a una reducción de las glándulas oxínticas $^{1-5}$. La forma adulta está asociada a una sobreexpresión del gen del factor transformador de crecimiento a (TGF- $\alpha$ ), compromete típicamente el cuerpo y fondo gástrico respetando el antro $^{3,4}$. Presentamos el caso de un paciente con enfermedad de Ménétrier que se manifestó con compromiso gástrico difuso con extensión a duodeno y realizamos una revisión del tema.

\section{Caso clínico}

Paciente sexo masculino, de 55 años, con antecedentes de tabaquismo crónico detenido y flegmón apendicular operado a los 40 años. Dos meses antes de consultar inició cuadro caracterizado por dolor abdominal difuso, asociado a vómitos de predominio vespertino, postprandiales mediatos y baja de 15 kilos de peso en este período. La endoscopía digestiva alta mostró la presencia de pliegues gástricos prominentes en forma difusa, lesiones solevantadas sésiles con ulceración central de fondo rojo y lesiones ulceradas duodenales, con test de ureasa positivo. Se realizaron biopsias informadas como gastritis crónica inespecífica y duodenitis. El estudio de laboratorio mostró: GOT 50 UI/L, GPT 56 UI/L, GGT 85 UI/L, FA 81 $\mathrm{UI} / \mathrm{L}$, hematocrito $55 \%$, tiempo de protrombina $100 \%$, creatininemia $1,2 \mathrm{~g} / \mathrm{dL}$, calcio total $7,8 \mathrm{mg} /$ $\mathrm{dL}$, proteinemia $4,4 \mathrm{~g} / \mathrm{dL}$, albuminemia $2,3 \mathrm{~g} / \mathrm{dL}$ y LDH 229 UI/ml. En la ecotomografía abdominal se informó esteatosis hepática.

Se indicó tratamiento de erradicación para Helicobacter pylori durante 14 días, observándose la persistencia de los vómitos, con intolerancia a alimentación oral, por lo que se decidió hospitalizar para manejo nutricional y realización de macrobiopsias gástricas.

A su ingreso al servicio de Gastroenterología de nuestro Hospital destacaba paciente con hemodinamia estable, afebril, mesomorfo, sin edema, ni palidez. Sin signos carenciales en piel, mucosas ni fanéreos. Los exámenes de laboratorio confirma- 

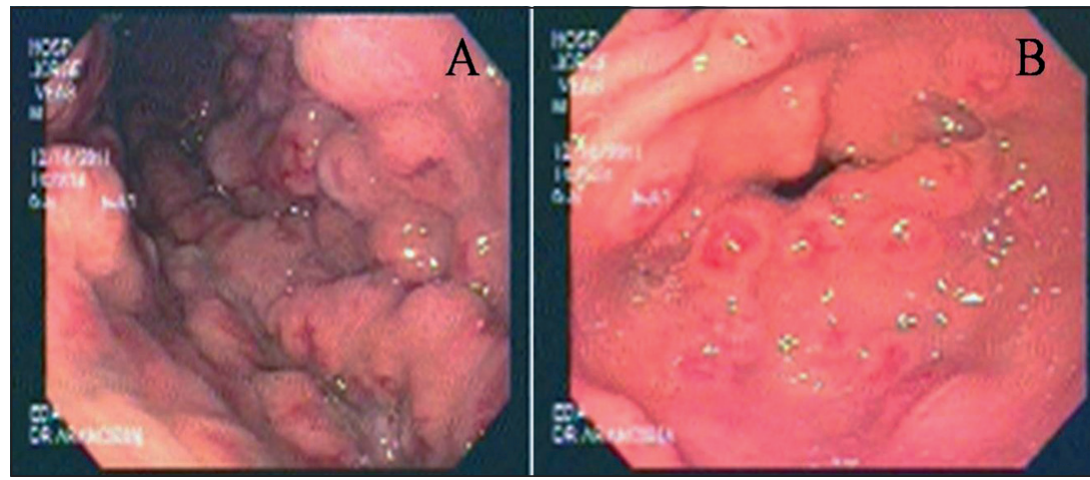

Figura 1. Endoscopia digestiva alta con pliegues gástricos engrosados en forma difusa. A: cuerpo gástrico. B: antro.

ron proteínas totales $3,5 \mathrm{~g} / \mathrm{dL}$, albuminemia $1,9 \mathrm{~g} / \mathrm{dL}$, proteinuria negativa y hemograma sin alteraciones.

\section{Evolución y exámenes de laboratorio posteriores}

Se efectúa tomografía axial computada (TAC) de abdomen-pelvis que muestra pliegues gástricos prominentes, enteroclisis por TAC informó ausencia de lesiones radiológicas en intestino delgado.

Se realizó endoscopía digestiva alta que mostró pliegues gástricos difusamente engrosados, algunos erosionados, test de ureasa negativo (Figura 1). Las biopsias fueron informadas como mucosa gástrica con hiperplasia foveolar difusa, asociada a atrofia glandular con dilataciones quísticas y células mucinosas. Erosión epitelial superficial focal con acúmulos de leucocitos polimorfonucleares, lámina propia con infiltrado inflamatorio escaso de predominio linfoplasmocitario, con algunos eosinófilos (Figura 2).

Se complementó estudio con endosonografía demostrándose engrosamiento gástrico a expensas de la mucosa profunda y áreas quísticas (Figura 3).

Ante la extensión de la lesión, el riesgo de transformación neoplásica y la no disponibilidad de cetuximab, se decidió tratamiento quirúrgico. Se solicitó evaluación por el equipo de nutrición, demostrándose prealbúmina, niveles de vitamina B12 y folato eritrocitario dentro de rangos normales. Se controlaron los vómitos con ondasentron,

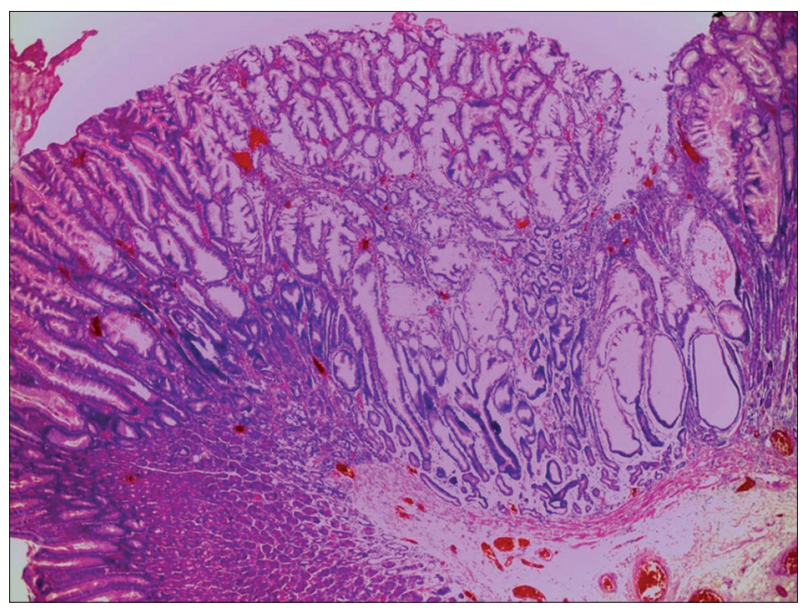

Figura 2. Biopsia gástrica con hiperplasia foveolar con foveolas tortuosas y dilatadas, dilatación quística con células mucinosas, atrofia glandular y escaso infiltrado inflamatorio (hematoxilinaeosina, aumento de $25 \mathrm{x}$ ).

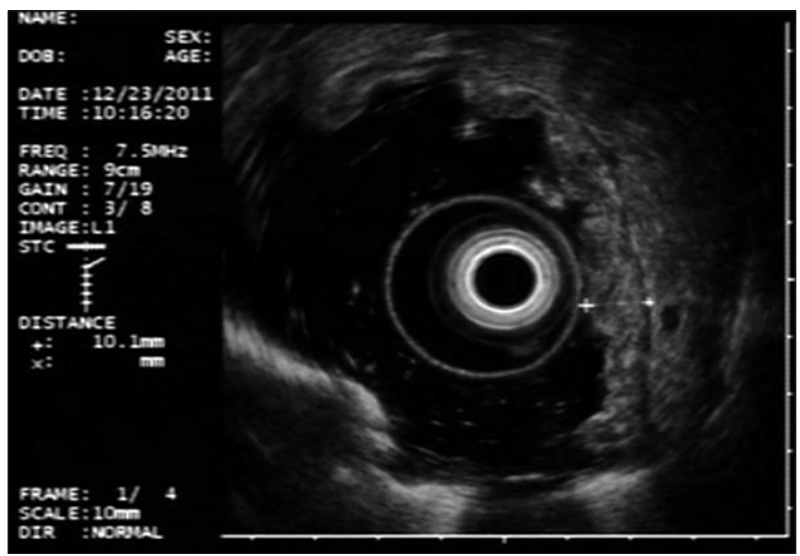

Figura 3. Endosonografía con engrosamiento de pliegues gástricos a expensas de la capa mucosa profunda y áreas quísticas. 


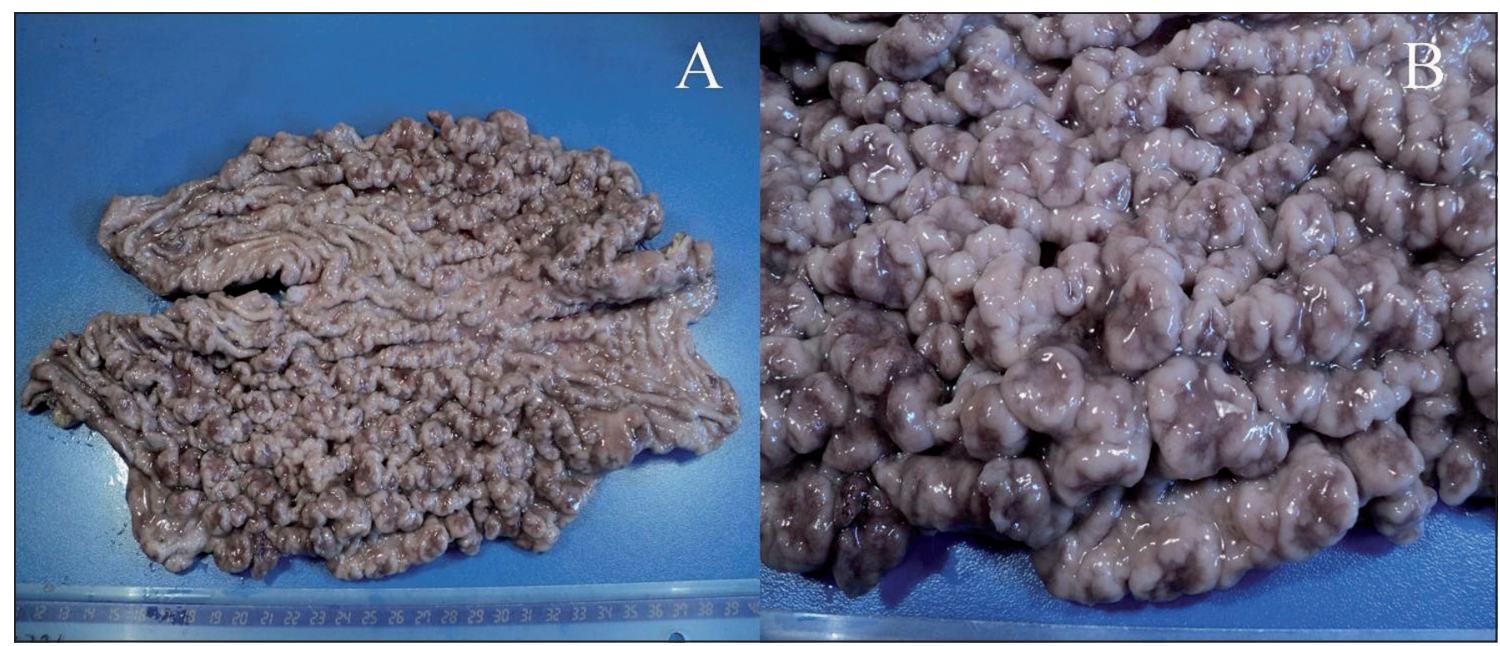

Figura 4. Pieza operatoria posterior a gastrectomía. A: engrosamiento de pliegues difuso en mucosa gástrica. B: acercamiento de pliegues gástricos engrosados.

logrando ingesta oral adecuada, se apoyó con nutrición parenteral por 7 días con lo cual aumentó la albuminemia a 2,3 gr/dl. A los 14 días de su ingreso se realizó una gastrectomía total, sin incidentes y el paciente evolucionó en forma favorable.

En el análisis macroscópico de la pieza operatoria se observó pared gástrica de espesor engrosado homogéneamente, mucosa con pliegues difusamente engrosados, congestivos, algunos con erosión superficial; rodete duodenal de 1,5 centímetros de diámetro, con lesión polipoide de 1 centímetro de eje mayor. En la histología se confirmaron los hallazgos descritos en las biopsias endoscópicas, con compromiso gástrico difuso, y en el duodeno en zona descrita de lesión polipoide se observó metaplasia fúndica focal con hiperplasia foveolar y atrofia glandular, con dilatación quística y células mucinosas. Se concluyó enfermedad de Ménétrier gástrica difusa con compromiso duodenal focal (Figura 4).

\section{Discusión}

La enfermedad de Ménétrier fue descrita por Pierre Ménétrier en 1888. Corresponde a una gastropatía hiperplásica poco frecuente, caracterizada por la presencia de pliegues gástricos engrosados asociada a pérdida de proteínas y en ocasiones hipoclorhidria. Es más frecuente en varones entre 50 y 60 años y se presenta clínicamente con do- lor abdominal, náuseas, vómitos, baja de peso y edema periférico debido a la pérdida de proteínas dada por la excesiva secreción de mucina a través de la mucosa gástrica ${ }^{1-5}$.

La enfermedad compromete típicamente el cuerpo y fondo gástrico, respetando en general el antro. Existen reportes aislados en la literatura de compromiso gástrico difuso y sólo dos reportes con compromiso duodenal: en el primer caso se describe compromiso de fondo gástrico y de mucosa fúndica heterotópica a nivel duodenal, y en el segundo se describe lesiones difusas nodulares que afectan todo el estómago y duodeno proximal, confirmándose histológicamente enfermedad de Ménétrier ${ }^{6,7}$.

La etiología de la enfermedad de Ménétrier se desconoce, se han postulado factores infecciosos como citomegalovirus y $H$. pylori que participarían principalmente en la forma infantil, habitualmente reversible en forma espontánea o secundario al tratamiento de la infección ${ }^{8-10}$. La forma adulta se ha relacionado a sobreexpresión gástrica del factor transformador de crecimiento a (TGF- $\alpha$ ) que corresponde al ligando del receptor de factor de crecimiento epidérmico (EGFR), lo que va seguido de hiperplasia de células mucosas superficiales, aumento en la producción de mucina, atrofia de células parietales y disminución de la producción de ácido en algunos pacientes ${ }^{4,11,12}$.

El diagnóstico de la enfermedad se basa en la sospecha clínica, la presencia en endoscopía 
e imágenes de pliegues gástricos engrosados y alteraciones histológicas características que incluyen hiperplasia foveolar, glándulas tortuosas y dilatadas, disminución de células parietales y leve infiltrado inflamatorio ${ }^{1-5}$. El diagnóstico diferencial debe considerar enfermedades gástricas que puedan causar engrosamiento de pliegues como síndromes polipósicos con compromiso gástrico, pólipos hiperplásicos, síndrome Cronkhitee Canada, linitis plástica y linfoma ${ }^{2,5}$. La endosonografía constituye una herramienta útil para el diagnóstico diferencial ya que permite evaluar las características de los pliegues gástricos engrosados, apoyando el diagnóstico de enfermedad de Ménétrier cuando el engrosamiento se origina en la mucosa profunda ${ }^{13,14}$.

La enfermedad de Ménétrier se ha asociado a mayor riesgo de cáncer gástrico, pero la magnitud de este riesgo es incierto y oscila entre $0-10 \%$ en la literatura ${ }^{2,15,16}$.

El tratamiento de la enfermedad se basa principalmente en el manejo quirúrgico, especialmente en pacientes con pérdida no controlable de proteínas y debido al posible riesgo de malignización ${ }^{2,3,17}$. En los casos asociados a infección por $H$. pylori o citomegalovirus se ha comunicado el control parcial de los síntomas luego del tratamiento de la infección. Se han utilizado tratamientos empíricos con antiácidos, anticolinérgicos, octreótido y prednisona, sin embargo, no existen evidencias sólidas de beneficios asociados a estas terapias ${ }^{1,3,11}$. La demostración del trastorno de señalización asociado a EGFR en la enfermedad de Ménétrier ha permitido el tratamiento con cetuximab, anticuerpo monoclonal que bloquea el sitio de unión de EGFR, con 7 casos comunicados en la literatura con respuesta favorable ${ }^{11,12,18}$. Sin embargo, el uso de cetuximab aún es considerado como tratamiento "compasivo" por parte de la FDA, por lo que el tratamiento de elección para la enfermedad de Ménétrier continúa siendo la gastrectomía total o parcial según el compromiso gástrico presente y las características clínicas. En el caso de nuestro paciente se realizó gastrectomía total dada la severidad de la enfermedad.

\section{Referencias}

1. Lambreht N. Ménétrier's disease of the stomach: a Clinical challenge. Curr Gastroenterol Rep 2011; 13: 513-7.
2. Ramia JM, Sancho E, Lozano O, Santos JM, Domínguez F. Enfermedad de Ménétrier y cáncer gástrico. Cir Esp 2007; 81 (3): 153-4.

3. Famularo G Sajeva MR Gasbarrone I. Beyond gastritis and before cancer: the strange case of Ménétrier's disease. Intern Emerg Med 2011; 6 (4): 369-71.

4. Coffey R, Washington M, Corless C, Heinrich M. Ménétrier disease and gastrointestinal stromal tumors: hyperproliferative disorders of the stomach. J Clin Invest 2007; 117 (1): 70-80.

5. Rich A, Zuluaga T, Tanksley J, Fiske W, Lind C, Ayers G et al. Distinguishing Ménétrier's disease from its mimics. Gut 2010; 59 (12): 1617-24.

6. Kemeny H, Boddaert A, Caubria P. Ménétrier's disease located at fundus and at heterotopic fundic mucosa in duodenum. Diagnosis by electrosurgical snare biopsy. Arch Anat Cytol Pathol 1980; 28 (6): 355-9.

7. $\mathrm{Wu} \mathrm{CS}$ Lin C), Chen TC, Chen PQ, Chiu CQ. Ménétrier's disease: a new variant with duodenal involvement. Am J Gastroentero 1997; 92 (6): 1041-3.

8. Hoffer V, Finkelstein Y, Balter , Feinmesser M, Garty B. Ganciclovir treatment in Menetrier's disease. Acta Paediatr 2003; 92 (8): 983-5.

9. Megged O, Schlesinger Y. Cytomegalovirus-associated protein-losing gastropathy in childhood. Eur J Pediatr 2008; 167 (11): 1217-20.

10. Fretzayas A, Moustaki M, Alexopoulou E, Nicolaidou P. Menetrier's disease associated with Helicobacter pylori: three cases with sonographic findings and a literature review. Ann Trop Paediatr 2011; 31 (2): 141-7.

11. Burdick JS, Chung EK, Thinner E, Ster M, Paciga JE, Cheng JQ et al. Treatment of Menetrier's disease with a monoclonal antibody against epidermical growth factor receptor. New Engl J Med 2000; 343 (23): 1697-701.

12. Nalle S, Turner J. Menetrier's disease therapy: rebooting mucosal signaling. Sci Transl Med 2009; 1 (8): 8-10.

13. Hizawa K Kawasaki M, Yao T, Aoyagi K, Suekane H, Kawakubo K et al. Endoscopic ultrasound features of protein-losing gastropathy with hypertrophic gastric folds. Endoscopy 2000; 32 (5): 394-7.

14. Ginès A, Pellise M, Fernández-Esparrach G, Soria MT, Mata A, Membrillo A, et al. Endoscopidfultrasonography in patients |with |large| $\mid$ gastrid |folds at endoscopy and biopsies|negative|for|malignancy:|predictors of malig hant|disease and clinical [impact. Am J Gastroentero] 2006; 101 (1): 64-9.

15. Meuwissen SG, Ridwan BU, Hasper $\mathrm{HJ}$, Innemee $\mathrm{G}$. Hypertrophic protein-losing gastropathy. A retrospective analysis of 40 cases in The Netherlands. The Dutch Ménétrier Study Group. Scand J Gastroenterol (Suppl) 1992; 194: 1-7. 
16. Pereyra L, Gómez E, Mella J, Casas G, Bugari G, Cimmino D, et al. Diffuse gastric cancer associated with Ménétrier's disease. A cta Gastroenterol Latinoam 2011; 41 (2): 142-5.

17. García-Alvarez MN P ata-Muñoz JD, Medina-Franco H. Total gastrectomy in the management of Ménétrie's disease. Institutional experience and review of the literature. Rev Gastroenterol Mex 2007; 72 (3): 244-8.

18. Fiske W, Tanksley , Nam K, Goldenring J, Slebos R, Liebler DC, et al. Efficacy of Cetuximab in the Treatment of Ménétrier's Disease. Sci Transl Med 2009; 1 (8): 11-8. 